\title{
UREA EXCRETION AT LOW URINE VOLUMES. THE CALCULATION OF "MINIMAL" UREA CLEARANCES
}

\author{
By LEON C. CHESLEY \\ (From the Department of Biochemistry, Margaret Hague Maternity Hospital, Jersey City)
}

(Received for publication August 2, 1937)

In a previous paper (1), it was shown that the calculation of standard urea clearances from urine volumes of less than about $0.35 \mathrm{ml}$. per minute gives results which are considerably too low. It was found that the lower the urine volume is, the greater the error becomes, as the calculated standard clearance falls lower and lower. This was demonstrated in 173 adults, including patients with toxemia of pregnancy, Bright's disease of almost all grades of severity, and in normal controls. Relevant published data of other writers fitted in with the trend of points on the graph summarizing these calculated clearances.

Most of the data reported in the previous paper were derived from routine renal function tests and represented only two, three, or four successive hourly clearances. It was seen that the source of error in calculating the standard clearances lay in the behavior of the urea concentration ratio (the ratio of urine urea to blood urea, $U / B$ ). This ratio stopped increasing when the urine volume fell below the critical limit of about $0.35 \mathrm{ml}$. per minute. It was suggested that possibly the concentration ratio even reversed its trend and fell with further volume decrease. This was observed in some cases.

To answer this question as to the behavior of the urea concentration ratio at low urine volumes, a series of clearances in successive periods is required. These data will be presented here. On the basis of the findings, a new calculation, the " minimal urea clearance" is suggested. This calculation applies for urine volumes up to 0.35 $\mathrm{ml}$. per minute $(21 \mathrm{ml}$. per hour, and $504 \mathrm{ml}$. per 24 hours).

\section{MATERIAL AND METHODS}

Series of urea clearance determinations were done on four normal adults, two patients with preeclamptic toxemia, and one patient with terminal malignant nephrosclerosis with cardiac decompensation. In the normals, a thirty to sixty- hour food and water fast was necessary to get the urine volume down to the desired level. In the toxemia patients, a twelve-hour fast sufficed, while the patient with nephrosclerosis required no preparation. Most of the clearances were done at hourly intervals, though some were for longer periods, up to three hours. Two of the normals voided their urine; all other measurements were made with catheterized specimens.

Van Slyke's (2) gasometric urease methods were used for both blood and urine urea. The blood urea was determined in the Folin-Wu filtrate.

Curves were fitted to the data by the method of least squares.

\section{RESULTS AND DISCUSSION}

The results of the excretion tests are graphically shown in Figure 1 ; these data are summarized in Table I. In all cases it may be seen that the data

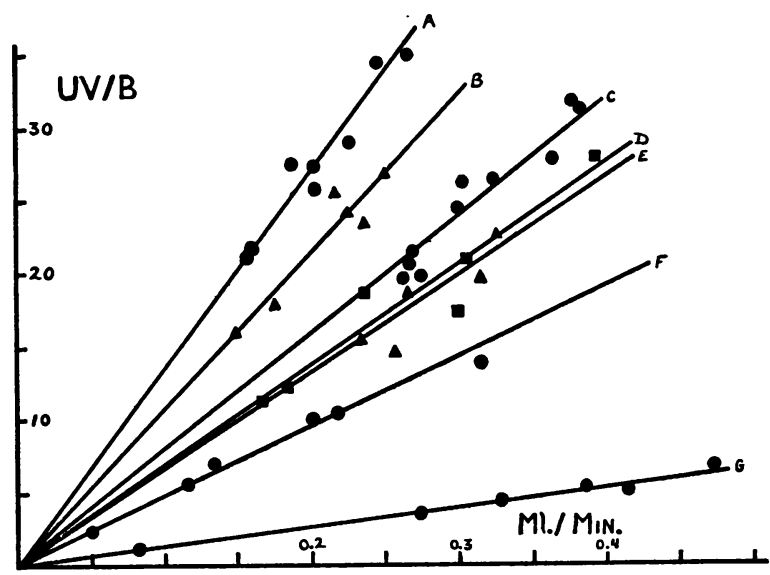

Fig. 1. The Dependence of the Urea Clearance $(U V / B)$ upon the Urine Volume. Lines Fitted by Method of Least Squares.

$$
\begin{aligned}
& A, B, C, \text { and } D=\text { Normals } \\
& E \text { and } F=\text { Preeclamptic toxemias } \\
& G=\text { Malignant nephrosclerosis }
\end{aligned}
$$

These lines show the constancy of the $U / B$ below the critical urine volume of about $0.35 \mathrm{ml}$. 
TABLE I

Urea excretion at low urine volumes

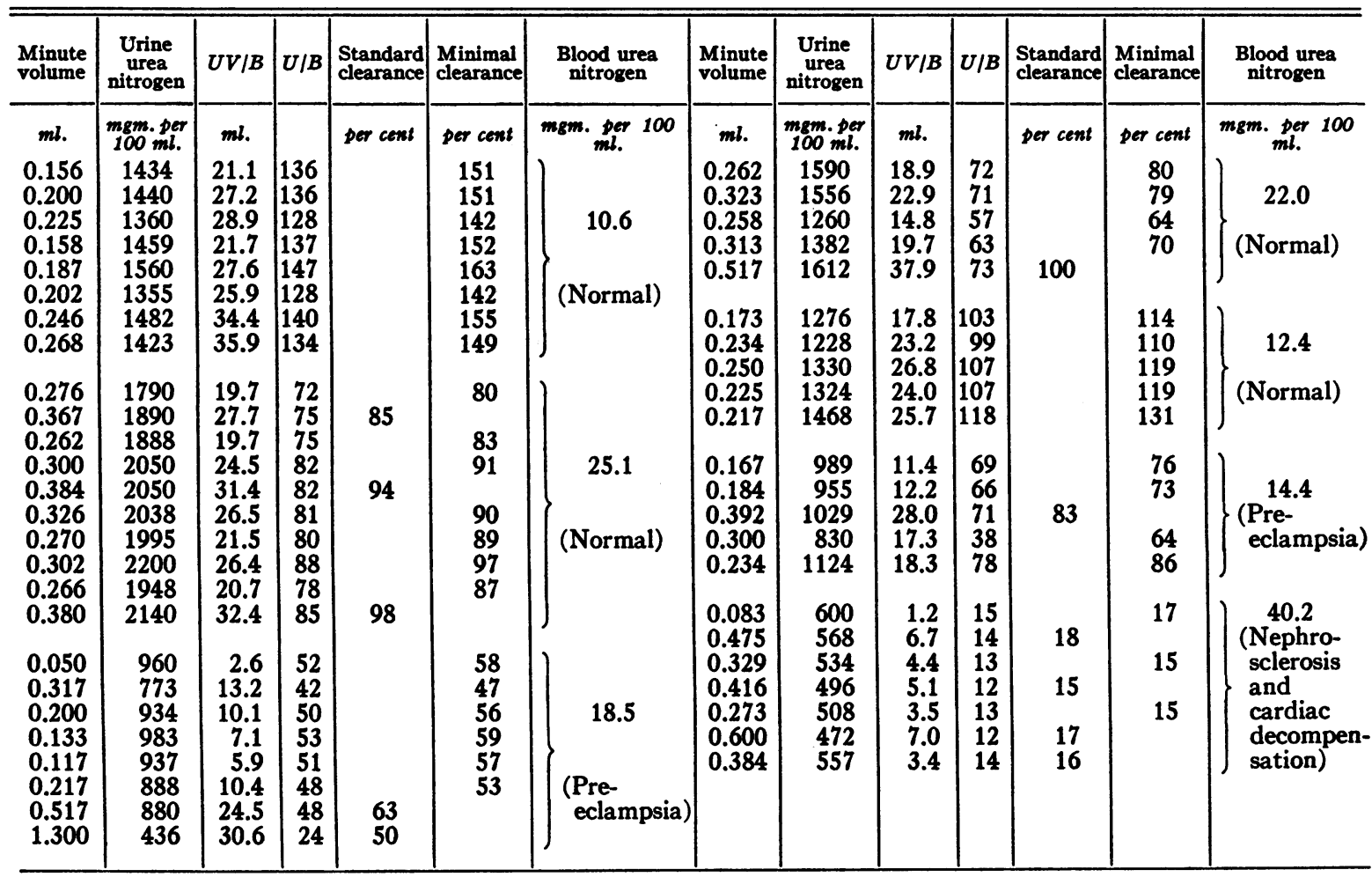

are fitted best by the straight lines, and that no other type of curve would seem to fit better. This applies in normal, toxemic, and nephritic subjects. All of the lines extrapolate to zero origin, and have been so drawn-not arbitrarily, but because the solution of the equations for the method of least squares gave a value of very nearly zero for $a$, in every instance.

The slopes of the lines shown in Figure 1 are given by the urea concentration ratio, $U / B$. If one were to assume that the urea clearances would fall along a straight line originating at zero, the lines could have been drawn from the average $U / B$ for each series. The fact that the lines are straight means, of course, that the $U / B$ is constant over the range of urine volumes considered. The suggestion that the $U / B$ might reverse its (increasing) trend below the critical volume is not supported. In pairs of clearances, one often sees a lower $U / B$ with the lower urine volume, when both volumes are near $0.35 \mathrm{ml}$. per minute. This must, apparently, be attributed to normal variations in renal activity, and perhaps to occa- sional failure to collect all of the urine for the given test period.

The "minimal" urea clearance. When the urine volume is in excess of about $2 \mathrm{ml}$. per minute, the "maximal" urea clearance is measured as $U V / B$. When the volume falls below $2 \mathrm{ml}$. per minute, the "standard" urea clearance is calculated from the formula $U \sqrt{V} / B$. That is, using the square root rule of Möller, McIntosh and Van Slyke (3), one calculates what the urea clearance would be if the urine volume were $1 \mathrm{ml}$. per minute. Since neither of the above formulae gives a constant when the urine volume is very low, it might be permissible to calculate a " minimal" urea clearance from volumes of less than about $0.35 \mathrm{ml}$. per minute.

In Figure 2 is shown the power curve describing the actual urea clearances, $U V / B$, which give standard clearances of 54 (100 per cent) when calculated as $U \sqrt{V} / B$. The equation for this curve is :

\section{Clearance $=54 \sqrt{\text { Minute urine volume. }}$}




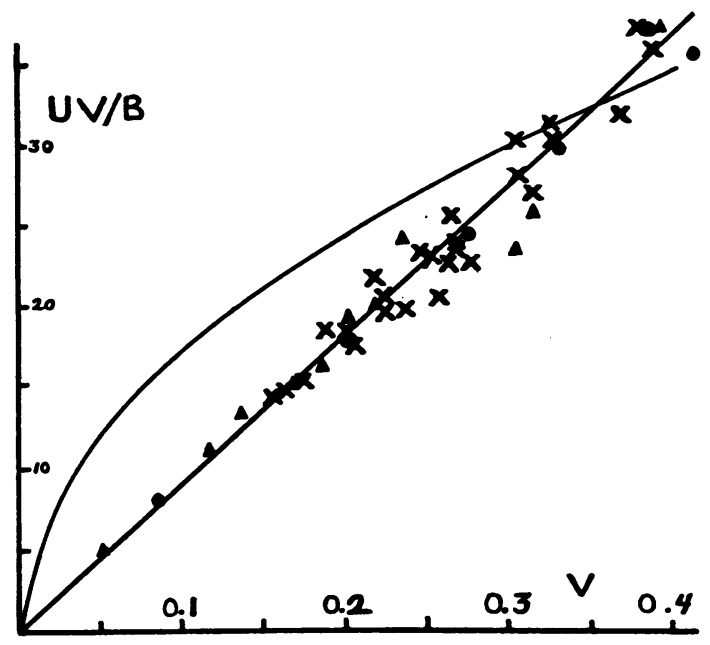

Fig. 2. Deviation of Urea Clearances, at Low Urine Volumes, from Theoretical Expected on Basis of Square Root Rule. Average of All Data Shown IN Figure 1.

Power curve $=$ square root rule clearances

$$
(y=54 \sqrt{V})
$$

Straight line $=$ trend of observed clearances

$$
(y=91.5 x)
$$

$X=$ Normal subjects

$\Delta=$ Preeclamptic patients

$=$ Patient with terminal malignant nephrosclerosis.

This figure forms the basis for the calculation of the " minimal" urea clearance.

The straight line is drawn so as to intersect the power curve at a urine volume of $0.35 \mathrm{ml}$. per minute, which is assumed to be the critical volume. The actual urea clearance here is $32 \mathrm{ml}$. of blood per minute; the $U / B$ which is given by the slope of the line is 91.5. The points which have been plotted with reference to this arbitrary line represent the data shown in Figure 1. The procedure was to determine the ratio of each line in Figure 1 to this line. Each point on each line was then multiplied by the appropriate factor and plotted with reference to the arbitrary line, thus averaging all data.

We see that the $U / B$ at $0.35 \mathrm{ml}$. per minute will be the same as it is observed to be at any lower volume. Hence, one might determine either the urea clearance, $U V / B$, or calculate the standard clearance, using the observed $U / B$ and assuming a minute output of $0.35 \mathrm{ml}$., disregarding the actual urine volume. If the $U V / B$ were meas- ured, one would take a clearance of $32 \mathrm{ml}$. of blood per minute as 100 per cent. If the standard clearance were calculated as suggested, the 100 per cent level would be, of course, $54 \mathrm{ml}$.

This calculation does not give the actual urea clearance, but then neither does the conventional calculation of the standard clearance. In both cases, one computes what the clearance would be at an arbitrary volume. In both, the point of the computation is to get a constant numerical value.

If the urea clearance be expressed in per cent rather than in milliliters of blood cleared, the above calculation of the "minimal" clearance may be simplified by getting the observed $U / B$ as per cent of the "perfect" $U / B-91.5$. Multiplying the $U / B$ by $1.11(100 / 91.5)$ will accomplish this.

Usually it would suffice merely to report the $U / B$ when the urine volume is so low. However, if one were graphing the progress of a nephritic patient, for instance, some value directly comparable with past and future urea clearances would be desirable. Also, when doing a routine ureà clearance, of two successive hourly determinations, comparable figures may be obtained when one urine volume is very low. Here, of course, the large error introduced by an incomplete urine collection would dictate that the test be discarded if the usual method of calculation were employed. If the "minimal" clearance be computed, the completeness of urine collection is immaterial so long as the output is actually less than $0.35 \mathrm{ml}$. per minute.

If the suggested calculation of " minimal " urea clearances be a valid procedure, the results thus obtained should check with calculated standard or measured maximal clearances obtained in the same subject when the urine volume is higher. The data reported in the previous paper are well suited for such comparisons. In these cases, successive hourly clearances were determined. In each pair or series, one or more clearances were determined with the urine volume below $0.35 \mathrm{ml}$. per minute, while one or more volumes were above 0.5 $\mathrm{ml}$. per minute. The data were derived from 173 normal, nephritic, and toxemic subjects, and from published figures of other writers. To this are now added observations on twenty-odd more patients and normal controls. 
There were in all 241 calculations of " minimal " urea clearances which can be compared with control clearances at higher urine volumes. These " minimal" clearances check very well with their controls. Nearly two-thirds of all check within

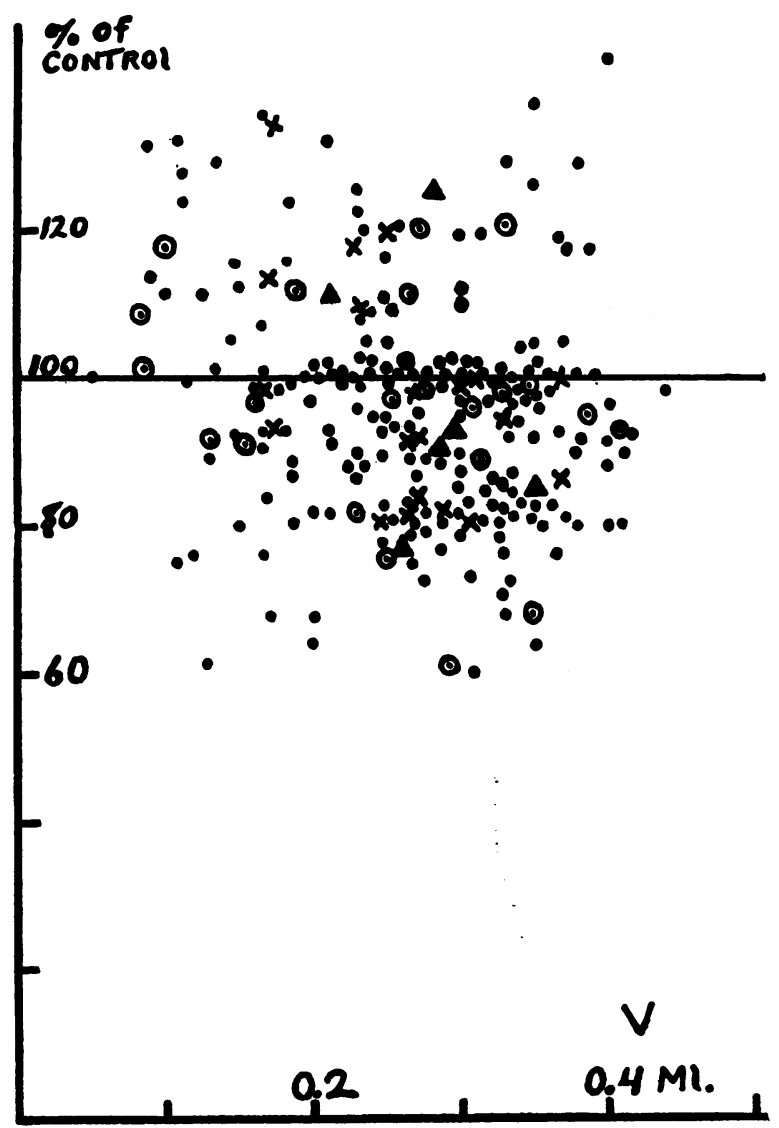

Fig. 3. Distribution of "Minimal" Urea Clearances about the Control at 100 Per Cent

The control is a valid standard or maximal clearance determined in the hour or hours following the "minimal" clearance determination.

$\times$ Normal adults.

- Toxemia of pregnancy.

$\odot$ Bright's disease complicated by pregnancy.

- Published data of Möller, McIntosh and Van Slyke (3).

15 per cent with the standard or maximal clearances. Taking the control clearances as 100 per cent, the average "minimal" urea clearance is 96.3 per cent. The distribution of these " minimal " clearances is shown in Figure 3, which may be summarized as follows:

\begin{tabular}{c|c|c|c|c|c}
\hline \hline Cases & Mean & Median & Mode & $\begin{array}{c}\text { Standard } \\
\text { deviation }\end{array}$ & $\begin{array}{c}\text { Coefficient } \\
\text { of skewness }\end{array}$ \\
\hline 241 & 96.3 & 97.5 & 99.4 & 15.18 & -0.237 \\
\hline
\end{tabular}

More " minimal" clearances fall below 100 per cent than above it (1.68:1), thus giving a skewed distribution curve. Perhaps this is explicable by the fact that most of the patients showed rising urine volumes, the control clearances being determinued in the last specimen(s). Chasis (4) has shown that the urea excretion, with rising urine volumes, increases more rapidly than it decreases with falling volumes. That is, the control clearances are too high. Failure of complete collection of the urine is another factor which must have vitiated some of the observations.

It is, perhaps, possible that the subjects represented in Figures 1 and 2 had a constant urine output and that varying amounts of the actual output were obtained at each collection. To check on this possibility, the bladder would have to be washed out at each urine collection. This possibility would prohibit any conclusions as to the actual excretion and tubular reabsorption of urea. However, in 241 observations in 200 adult subjects, "minimal" clearance calculations give constants which are comparable with the constants obtained from the conventional computation of standard and maximal clearances. Standard clearance calculations from such low volumes do not give constants. These empirical findings would seem to justify the suggestion that " minimal" clearances be calculated when the urine volume is low. Whether the actual urine output is obtained or not is beside the point, since in this large series the clearances were done as routine clearance tests of renal function are almost always done, i.e., with catheterized bladder specimens, or in some cases, with voided urines.

\section{SUMMARY AND CONCLUSIONS}

When the urine volume falls below a critical level of about $0.35 \mathrm{ml}$. per minute, the urea concentration ratio apparently becomes fixed. Further decrease in urine volume does not seem to affect the $U / B$. 
It is proposed that in oliguria " minimal " urea clearances be calculated. A formula is provided which gives a constant comparable with the constants obtained from standard and maximal clearance calculations.

Two hundred forty-one " minimal" clearances are compared with standard or maximal controls, and shown to check satisfactorily.

I wish to acknowledge my indebtedness to Dr. S. A. Cosgrove for his interest in this work, and for the use of his private as well as ward patients.

\section{BIBLIOGRAPHY}

1. Chesley, L. C., The validity of the calculation of standard urea clearances from low urine volumes. J. Clin. Invest., 1937, 16, 653.

2. Van Slyke, D. D., Determination of urea by gasometric measurement of the carbon dioxide formed by the action of urease. J. Biol. Chem., 1927, 73, 695.

3. Möller, E., McIntosh, J. F., and Van Slyke, D. D., Studies of urea excretion. II. Relationship between urine volume and the rate of urea excretion by normal adults. J. Clin. Invest., 1929, 6, 427.

4. Smith, H. W., The Physiology of the Kidney. Oxford University Press, New York, 1937, p. 131. 